\title{
Human PrP90-231-induced cell death is associated with intracellular accumulation of insoluble and protease-resistant macroaggregates and lysosomal dysfunction
}

\author{
S Thellung ${ }^{1}$, A Corsaro ${ }^{1}$, V Villa ${ }^{1}$, A Simi ${ }^{1,2}$, S Vella ${ }^{2}$, A Pagano $^{1,2}$ and T Florio ${ }^{\star, 1,3}$
}

To define the mechanisms by which $\mathrm{hPrP90-231}$ induces cell death, we analyzed its interaction with living cells and monitored its intracellular fate. Treatment of SH-SY5Y cells with fluorescein-5-isothiocyanate (FITC)-conjugated hPrP90-231 caused the accumulation of cytosolic aggregates of the prion protein fragment that increased in number and size in a time-dependent manner. The formation of large intracellular hPrP90-231 aggregates correlated with the activation of apoptosis. hPrP90-231 aggregates occurred within lysotracker-positive vesicles and induced the formation of activated cathepsin $D(C D)$, indicating that hPrP90-231 is partitioned into the endosomal-lysosomal system structures, activating the proteolytic machinery. Remarkably, the inhibition of CD activity significantly reduced hPrP-90-231-dependent apoptosis. Internalized hPrP90-231 forms detergentinsoluble and SDS-stable aggregates, displaying partial resistance to proteolysis. By confocal microscopy analysis of lucifer yellow (LY) intracellular partition, we show that hPrP90-231 accumulation induces lysosome destabilization and loss of lysosomal membrane impermeability. In fact, although control cells evidenced a vesicular pattern of LY fluorescence (index of healthy lysosomes), hPrP90-231-treated cells showed diffuse cytosolic fluorescence, indicating LY diffusion through damaged lysosomes. In conclusion, these data indicate that exogenously added hPrP90-231 forms intralysosomal deposits having features of insoluble, protease-resistant aggregates and could trigger a lysosome-mediated apoptosis by inducing lysosome membrane permeabilization, followed by the release of hydrolytic enzymes.

Cell Death and Disease (2011) 2, e138; doi:10.1038/cddis.2011.21; published online 31 March 2011

Subject Category: Neuroscience

Transmissible spongiform encephalopathies (TSE) are fatal neurodegenerative disorders characterized by spongiform degeneration of the brain, neuronal loss, gliosis, and amyloid deposition. According to the 'protein only' hypothesis, TSEs share, as crucial pathogenic event, the posttranslational misfolding of a membrane-anchored glycoprotein (cellular prion protein, $\mathrm{PrP}^{\mathrm{C}}$ ) into a protease-resistant, aggregationprone isoform $\left(\mathrm{PrP}^{\mathrm{Sc}}\right) .{ }^{1} \mathrm{PrP}^{\mathrm{Sc}}$ is thought to be the main, if not the sole, component of the infectious entity of TSE (the prion). $\mathrm{PrP}^{\mathrm{C}}-\mathrm{PrP}^{\mathrm{Sc}}$ conversion, physiologically prevented by energy barrier, may be a spontaneous stochastic event, favored by mutations in the PRNP gene, or acquired by infection with exogenous $\mathrm{PrP}^{\mathrm{Sc}}$. $\mathrm{PrP}^{\mathrm{Sc}}$ resistance to proteolysis determines its deposition, as partially cleaved protein, in extracellular space and the formation of amyloid plaques. ${ }^{1} \mathrm{PrP}^{\mathrm{Sc}}$ deposits are often identified in proximity of neuronal rarefaction and gliosis, suggesting their possible involvement in inflammatory and apoptotic cascades. ${ }^{2}$ Recombinant $\operatorname{PrP}$ fragments corresponding to the protease-resistant portion of $\mathrm{PrP}^{\mathrm{Sc}}$ have been used to study PrP pathogenic refolding and neurotoxicity being characterized by a flexible backbone that can undergo conformational rearrangement resembling $\mathrm{PrP}^{\mathrm{C}}-\mathrm{PrP}^{\mathrm{Sc}}$ conversion. ${ }^{3,4}$ Although a definitive agreement is still lacking, it was demonstrated that $\mathrm{PrP}^{\mathrm{Sc}}$-like fragments can generate disease after cerebral inoculation in rodents. ${ }^{5,6}$ We generated a recombinant protein encompassing residues 90-231 of human PrP (hPrP90-231) that, in its native form, is a soluble monomer, mainly structured as $\alpha$-helix. ${ }^{7}$ Controlled thermal denaturation $\left(1 \mathrm{~h}\right.$ at $\left.53^{\circ} \mathrm{C}\right)$ converts $\mathrm{hPrP} 90-231$ in a $\beta$-sheetrich conformation that renders the peptide insoluble, highly hydrophobic, and partially resistant to proteolysis. ${ }^{3,8}$ These biochemical features, resembling $\mathrm{PrP}^{\mathrm{Sc}}$-like structure, allow hPrP90-231 to acquire biological activities in vitro, inducing microglial activation, astrocyte proliferation, and neuron apoptosis,, ${ }^{3,9}$ thus, representing a valuable model to study prion neurotoxicity and the potential development of novel therapeutics. ${ }^{10,11}$

To define the mechanism of hPrP90-231 effects on cell viability, we used SH-SY5Y human neuroblastoma cells. These cells are sensitive to PrP fragment toxicity through the intracellular accumulation of hPrP90-231 oligomers within the vesicular system. ${ }^{3,12}$ The identification of intracellular

\footnotetext{
${ }^{1}$ Laboratory of Pharmacology, Department of Oncology, Biology and Genetics University of Genova, Genova, Italy; ${ }^{2}$ Department of Regenerative Medicine, National Institute for Cancer Research (IST) Genova, Genova, Italy and ${ }^{3}$ Center of Excellence for Biomedical Research (CEBR), University of Genova, Genova, Italy ${ }^{*}$ Corresponding author: T Florio, Laboratory of Pharmacology, Department of Oncology, Biology and Genetics, University of Genova, Viale Benedetto XV, 2, 16132 Genova, Italy. Tel/Fax: + 39010 3538806; E-mail: tullio.florio@unige.it

Keywords: prion protein; prion diseases; apoptosis; cell internalization; proteinase $\mathrm{K}$ resistence; lysoome dysfunction

Abbreviations: CD, cathepsin D; Dil, 1,1'-dioctadecyl-3,3,3',3'-tetramethylindocarbocyanine perchlorate; FITC, fluorescein-5-isothiocyanate; LY, lucifer yellow; PeP A, pepstatin A; PK, proteinase K; PrP, prion protein; TSE, transmissible spongiform encephalopathy

Received 11.8.10; revised 03.2.11; accepted 17.2.11; Edited by A Verkhrasky
} 
hPrP90-231 deposits was a relevant starting point of this study as intracellular accumulation of misfolded and uncleavable proteins represents a pathogenetic event in several neurodegenerative disorders. ${ }^{13}$ Misfolded PrP deposits were described inside neuron cell bodies and in correspondence with axons and dendrites, ${ }^{14}$ being involved in neuronal apoptosis by perturbing energy metabolism, protein homeostasis, or axonal transport. TSE-related neuronal rarefaction occurs in brain areas characterized by lysosomal overloading with $\mathrm{PrP}^{\mathrm{Sc}},{ }^{15,16}$ suggesting that released lysosome proteases may contribute to neuronal death. Lysosome membrane permeabilization, releasing cathepsins, elicits the activation of proteins (caspases, BID, XIAPs), ${ }^{17}$ crucial for mitochondriamediated apoptosis. Cathepsin release from lysosomes is triggered by several proapoptotic stimuli, including oxidative stress, cytotoxic drugs, ${ }^{18}$ and also after $\mathrm{A} \beta 1-42$ intracellular accumulation in Alzheimer disease models. ${ }^{19}$

To address lysosome involvement in hPrP90-231 neurotoxicity, we treated SH-SY5Y cells with a fluorescein5-isothiocyanate (FITC)-tagged form of this peptide (hPrP90231-FITC) and monitored, by live cell imaging, its intracellular accumulation. We show that hPrP90-231-FITC accumulates in the endosomal-lysosomal system and activates cathepsin D (CD). hPrP90-231-FITC intracellular accumulation was correlated with the detection of apoptosis, suggesting that lysosomal overloading is a causal event in SH-SY5Y cell death. Indeed, pharmacological inhibition of $C D$ reduced hPrP90-231 apoptosis.

These data indicate that hPrP90-231 toxicity is mediated by lysosome-dependent apoptosis stimulated by lysosome overloading with proteolysis-insensitive protein aggregates.

\section{Results}

PrP90-231-FITC accumulates in SH-SY5Y cytoplasm in time-dependent manner as membrane-surrounded aggregates. Thermally denatured $\beta$-sheet-rich hPrP90-231 oligomers induce apoptosis in SH-SY5Y cells through the cytoplasmic accumulation of the peptide. ${ }^{12,20}$

Here, we used a FITC-tagged hPrP90-231 to precisely identify its subcellular localization and discriminate between the recombinant fragment and endogenous $\mathrm{PrP}^{\mathrm{C}}$. Preliminarily, we verified that the FITC tag did not alter the physicochemical and biological features of hPrP90-231, showing that it retains partial resistance to proteinase $\mathrm{K}(\mathrm{PK})$ digestion and conformation-dependent cytotoxicity, with efficacy similar to the untagged peptide (data not shown).

To investigate the mechanisms of hPrP90-231-FITC activation of apoptosis, we analyzed, by confocal microscopy, the presence of cytosolic aggregates of internalized PrP fragment (Figure 1a). Cells treated with thermally denatured hPrP90-231-FITC showed numerous intracytoplasmic fluorescent spots that became large clusters, in a time-dependent manner. FITC-conjugated $\alpha$-helix-structured hPrP90-231 accumulated in SH-SY5Y cytoplasm at lower rate than $\beta$-sheet-rich hPrP90-231-FITC, resulting in smaller aggregates (Figure 1a). We quantified the cell number that internalized the two hPrP90-231-FITC conformers (Figure 1b) showing that, after $24 \mathrm{~h}$ of treatment, the $\beta$-sheet-rich PrP fragment was accumulated in the double of the cells that internalized the $\alpha$-helix-structured hPrP90-231.

To detect whether hPrP90-231 intracellular accumulation was caused by entrapment within the vesicular system or by protein aggregation into the cytosol, we incubated SH-SY5Y cells with the lipophilic dye $1,1^{\prime}$-dioctadecyl-3,3,3',3'-tetramethylindocarbocyanine perchlorate (Dil) before hPrP90231-FITC treatment (Figure 1c). Live cell imaging showed that hPrP90-231 binds to the cell membrane within 5 min and can be recovered, after $6 \mathrm{~h}$, into the cytosol as discrete clusters colocalizing with the membrane fluorescent probe (Figure 1c). After longer treatments, large hPrP90-231-FITC clusters, clearly surrounded by Dil fluorescence, were detected, indicating that intracellular hPrP90-231 aggregates are caged into membrane-coated vesicles. Conversely, we did not detect hPrP90-231 aggregates not colocalized with Dil, signifying that hPrP90-231 does not diffuse through the plasma membrane to aggregate into the cytosol.

SH-SY5Y overloading with hPrP90-231 correlates with the activation of the apoptotic process. Then, we quantified the time- and structure-dependency of hPrP90231-induced apoptosis, measuring by ELISA, the cytosolic oligonucleosomes released by apoptotic endonucleases. We show that $\alpha$-helix-structured hPrP90-231 induced modest DNA cleavage, only after 3 days of treatment. In contrast, cell exposure to $\beta$-sheet-structured hPrP90-231 caused a significant accumulation of cytosolic oligonucleosomes already after $24 \mathrm{~h}$, reaching its maximal effect after 3 days of treatment (about threefolds higher than controls, Table 1).

To correlate hPrP90-231 intracellular accumulation and activation of apoptosis, we treated SH-SY5Y cells with hPrP90-231-FITC and assessed, in live cell imaging, the onset of apoptosis by annexin- $V$ binding test (Figure 2). Control cells did not show annexin- $V$ binding to the membrane, indicating the absence of apoptotic cells within the culture. Conversely, hPrP90-231-FITC treatment $(100 \mathrm{nM}$, $72 \mathrm{~h}$ ) caused a strong annexin- $\mathrm{V}$ staining on the plasma membrane, indicating the activation of apoptosis in a significant number of cells. Annexin-V-positive cells showed round and shrunk bodies (typical of apoptotic cells) and evidenced high amounts of internalized hPrP90-231-FITC (Figure 2-B, yellow arrows), whereas cells that internalized low levels of peptide did not undergo to apoptosis (Figure 2, white arrows). We estimated that, for each given time point, more than $10 \%$ of treated cells were annexin-V and hPrP90231-FITC-positive, although the low adherence of apoptotic cells surely caused underestimation of the total apoptotic cells number. Thus, hPrP90-231 induces apoptosis when a high hPrP90-231n cell loading occurs, whereas the interaction between hPrP90-231 and plasma membrane may not induce per se neurotoxicity if it is not followed by internalization of the PrP fragment. To better quantify the extent of apoptosis linked to hPr90-231 internalization, we measured, by flow cytofluorimetry, the percentage of cells showing overlapping hPrP90-231-FITC and annexin-V staining. We treated SH-SY5Y cells with $\beta$-sheet-rich hPrP90-231-FITC $(1 \mu \mathrm{M}$, 3 days), before annexin- $V$ staining (Figure 2, lower panels). Only $4 \%$ of control cells were annexin-V positive (Figure $2 \mathrm{~A}$, 


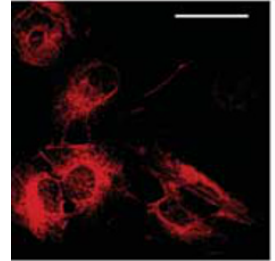

Untreated
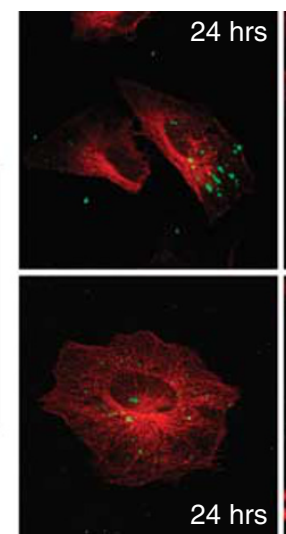

24 hrs
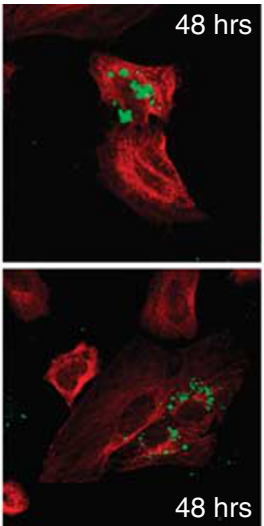

$\alpha-h P r P 90-231-F I T C$ c
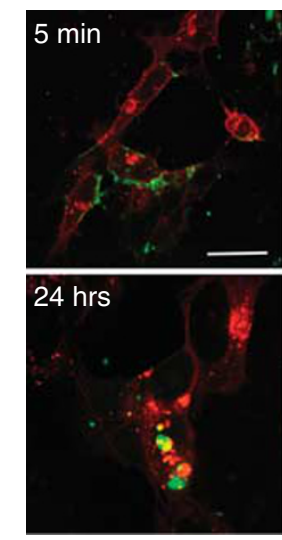

$\beta$-hPrP90-231-FITC/Dil
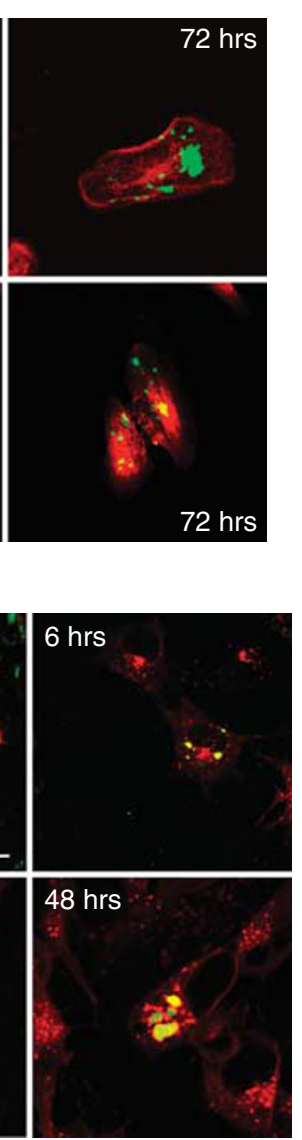

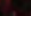

Figure 1 hPrP90-231 accumulates in SH-SY5Y in a structure-dependent manner. (a) Cells were plated on glass coverslips and treated for 24-72h with $\alpha-$ and $\beta$-hPrP90-231-FITC $(100 \mathrm{nM})$. After treatments, cells were fixed and immunostained for $\alpha$-tubulin to evidence the cell shape. Images, representative of at least three experiments, show that $\beta$-hPrP90-231-FITC is internalized as intracellular fluorescent clusters that condensed in a time-dependent manner. Conversely, $\alpha$-hPrP90-231-FITC treatment caused the internalization of small fluorescent clusters that did not evidence a significant condensation. (Scale bar $=10 \mu \mathrm{m}$ ). (b) Structure-dependent hPrP90-231 internalization. After exposure to $\alpha-(\bigcirc)$ and $\beta-(O) \mathrm{hPrP} 90-231-\mathrm{FITC}(100 \mathrm{nM})$ for 6,24 , and $48 \mathrm{~h}$, cells containing fluorescent clusters have been counted and plotted as percentages of total cells. The percent of cells showing intracellular FITC after exposure to $\beta$-hPrP90-231-FITC is significantly higher than that observed in cells treated with $\alpha$-hPrP90-231-FITC. Values represent the averages of three experiments conducted counting at least 500 cells/dish. ${ }^{*} P<0.05,{ }^{* *} P<0.01$ versus $\alpha-\mathrm{hPrP} 90-231-\mathrm{FITC}$ treated cells. (c) Live cell imaging of hPrP90-231-FITC intracellular accumulation in the presence of the membrane dye Dil. Cells were plated in glass-bottom Petri dishes, loaded with membrane-specific fluorescent dye Dil for $1 \mathrm{~h}$, and incubated with $\beta$-hPrP90-231-FITC (100 nM). Images (representative of three experiments) show that $\beta$-hPrP90-231-FITC binding to plasma membranes occur within few minutes. Treatment with $\beta$-hPrP90-231-FITC for $6 \mathrm{~h}$ evidenced the presence of intracellular fluorescent clusters that colocalizes with the membrane-specific probe Dil, indicating that $\beta$-hPrP90-231 accumulates in membrane-coated vesicles. Treatments for 24 and $48 \mathrm{~h}$ resulted in the intracellular accumulation of large FITC-stained, round clusters almost completely colocalizing with Dil. (Scale bar $=10 \mu \mathrm{m}$ )

Table 1 Induction of apoptosis in SH-SY5Y cells by hPrP90-231

\begin{tabular}{|c|c|c|c|c|}
\hline Days of treatment & 1 & 2 & 3 & 4 \\
\hline $\begin{array}{l}\alpha \text {-hPrP90-231 } \\
\beta \text {-hPrP90-231 }\end{array}$ & $\begin{array}{l}102 \pm 0.3 \\
127 \pm 0.19^{\star} \circ\end{array}$ & $\begin{array}{l}112 \pm 0.21 \\
190 \pm 0.13^{\star \star} \text { O० }\end{array}$ & $\begin{array}{l}133 \pm 0.2^{\star} \\
297 \pm 0.12^{\star \star ~ O ० ~}\end{array}$ & $\begin{array}{l}120 \pm 0.15^{\star} \\
250 \pm 0.3^{\star \star} \circ \circ\end{array}$ \\
\hline
\end{tabular}

hPrP90-231, in native structure ( $\alpha$-hPrP90-231) or in a $\beta$-sheet-rich conformation ( $\beta$-hPrP90-231), was used at the concentration of $1 \mu \mathrm{M}$. Apoptosis was quantified by cytosolic oligonucleosome ELISA, after 1-4 days. Data were expressed as percentage of PBS-treated controls and represents the average of three independent experiments performed in quadruplicate ${ }^{\star} P<0.05$, ${ }^{\star \star} P<0.01$ versus cont. values. ${ }^{\circ} P<0.05$, ${ }^{\circ 0} P<0.01$ versus samples treated with $\alpha$-hPrP90-231

lower panel, R2), indicating low amount of spontaneous apoptosis. hPrP90-231-FITC-treated cells showed annexin-V binding in $11.37 \%$ of cells (Figure $2 \mathrm{~B}$, lower panel, R3), thus indicating a threefold increase of apoptosis compared with controls. Importantly, almost all treated cells were stained with
hPrP90-231-FITC (Figure 2B, lower panel, R3 + R5), but only part of them entered the apoptotic pathway in agreement with the observation (Figure 2 upper panels) that elevated intracellular accumulation of hPrP90-231 is required to induce cell death. 
A

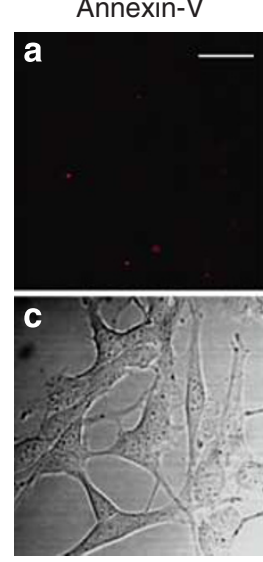

Phase-contrast

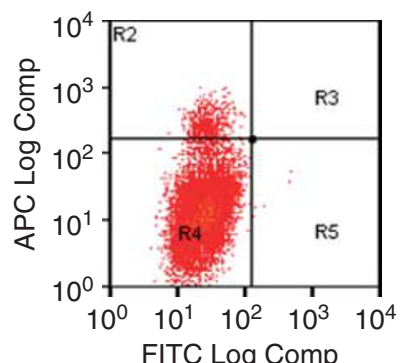

Vehicle
FITC

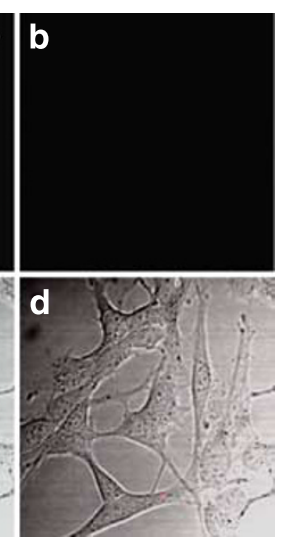

Merge
B
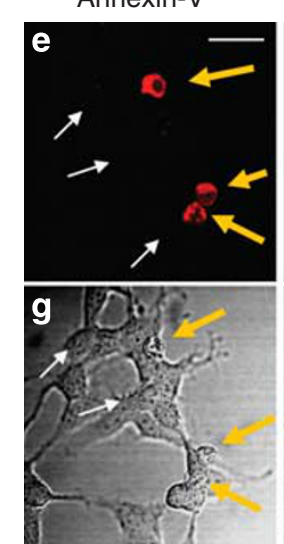

Phase-contrast

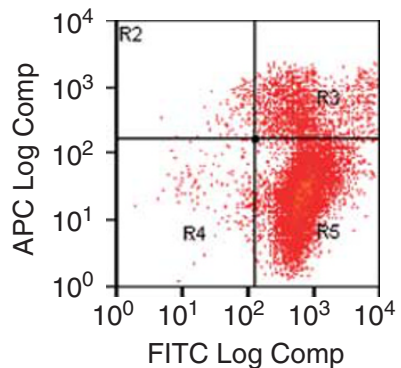

$\beta$-hPrP90-231-FITC

Figure 2 SH-SY5Y overloading with hPrP90-231 correlates with apoptosis onset. Upper panels. Live cell imaging of apoptosis onset in SH-SY5Y cells treated for $72 \mathrm{~h}$ with vehicle (A, a-d) or $\beta$-hPrP90-231-FITC (100 nM) (B, e-h). Apoptosis was assessed by annexin-V binding assay. Control cells (a-d) did not evidence red fluorescence, indicating the absence of annexin-V binding (a). Upon $\beta$-hPrP90-231-FITC treatment, red fluorescent rings were detected, indicating apoptosis-induced PS exposure on the external layer of plasma membranes (e, yellow arrows) that was paralleled by the internalization of large amounts of fluorescent PrP fragment in several cells (f, yellow arrows). In cells in which only small quantities of $\beta$-hPrP90-231-FITC were detected (f, white arrows), we did not observe annexin $\beta$-hPrP90-231-FITC binding. Phase-contrast pictures ( $\mathbf{g}$ and $\mathbf{h}$ ) evidences that the treatment with $\beta$-hPrP90-231-FITC caused cell body shrinkage. Images in panel $\mathrm{H}$ show that cell loading with high amounts of $\beta$ hPrP90-231-FITC correlate with annexin-V staining and cell body shrinkage ( $h$, yellow arrows). (Scale bar $=10 \mu \mathrm{m}$ ). Lower panels. Apoptosis measurement by flow cytometry of annexin-V binding. SH-SY5Y cells were treated for 3 days with vehicle $(\mathbf{A})$ and $\beta$-hPrP90-231-FITC $(1 \mu \mathrm{M})(\mathbf{B})$. Vehicle-treated cells showed a $3.97 \%$ of positivity to annexin-V (A, R2); $\beta$-hPrP90-231-FITC treatment induced FITC staining in more than $87 \%$ of the cells (B, R5) and increased the percentage of annexin-V-positive/FITC positive cells to 11.37 (B, R2) compared with untreated controls. Less than $1 \%$ of annexin-V-positive, FITC-negative (B, R2) cells were recorded

Internalized hPrP90-231 forms SDS-stable aggregates. We used semi-denaturing detergent-agarose gel electrophoresis to assess the formation of hPrP90-231 intracellular aggregates. $^{20-22} \mathrm{SH}-\mathrm{SY} 5 \mathrm{Y}$ cells, treated with vehicle or hPrP90-231 $(1 \mu \mathrm{M})$ were lysed and protein electrophoresis performed in non-denaturing conditions to preserve hPrP90231 intermolecular bonds and separate aggregates according to the their dimensions (Figures 3a and b). A separate set of samples was denatured and resolved by a standard SDSPAGE to identify the molecular weight of endogenous $\operatorname{PrP}^{\mathrm{C}}$ and internalized hPrP90-231 (Figures $3 \mathrm{c}$ and d). We also used two antibodies able to discriminate hPrP90-231 from PrP'; 3F4 antibody recognizes both proteins, 8B4 antibody labels the first 60-80 a.a. of PrP and does not detect hPrP90-231. In control cells, 3F4 and 8B4 evidenced two discrete bands, likely corresponding to endogenous $\operatorname{PrP}^{\mathrm{C}}$ (Figures $3 \mathrm{a}$ and $\mathrm{b}$, lanes 2). In treated cells, large hPrP90-231 aggregates were detected as 3F4-reactive proteins of high molecular weight (Figure 3a, lanes 3,4 ), but distributed throughout the electrophoretic lanes, indicating that internalized hPrP90-231 is recovered in macroaggregated complexes of different size. hPrP90-231 intracellular content and electrophoretic mobility were similar after 1 or 4 days of treatment (Figure $3 a$, lanes 3,4 ), demonstrating that hPrP90-231 aggregation state is not significantly affected by cell catabolic machinery. 8B4immunoreactive signal in hPrP90-231-treated cells was not changed with respect to controls (Figure 3b, lanes 3, 4) signifying that $\mathrm{PrP}^{\mathrm{C}}$ does not aggregate after hPrP90-231 internalization. SDS-PAGE showed that intracellular hPrP90231 aggregates are composed by $16 \mathrm{kDa}$ monomers (Figure $3 \mathrm{c}$ ) and do not alter $\mathrm{PrP}^{\mathrm{C}}$ expression (Figure 3d).

Intracellular hPrP90-231 aggregates are insoluble in non-denaturing detergents. Solubility in non-denaturing detergents is a commonly used parameter that discriminates $\mathrm{PrP}^{\mathrm{C}}$ from $\mathrm{PrP}{ }^{\mathrm{Sc}}$, the latter being less soluble. ${ }^{23}$ Structural alterations induced by hPrP90-231 thermal denaturation results in increased exposure of hydrophobic residues to the solvent in cell-free experiments. ${ }^{4}$ To obtain an index of the hydrophobicity of hPrP90-231 intracellular aggregates, we measured detergent solubility of internalized hPrP90-231. 
a

b

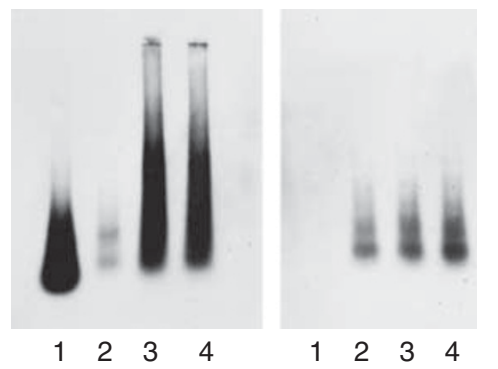

C

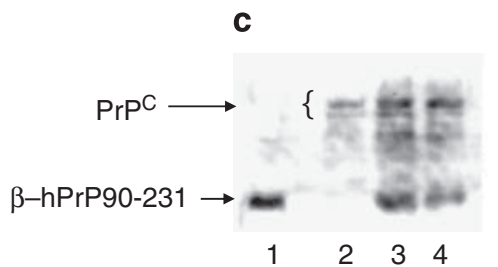

d

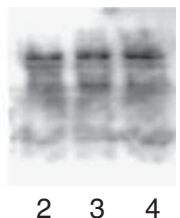

Figure 3 Internalized $\beta$-hPrP90-231 forms SDS-stable aggregates. Cells were treated with vehicle (lanes $2 \mathbf{a}-\mathbf{d}$ ) or $\beta$-hPrP90-231 $(1 \mu \mathrm{M})$ for 1 (lanes $3 \mathbf{a}-\mathbf{d}$ ) and 4 days (lanes $4 \mathbf{a}-\mathbf{d})$. Total cell lysates $(100 \mu \mathrm{g})$ were resolved by semi-denaturing detergent-agarose gel electrophoresis ( $\mathbf{a}$ and $\mathbf{b}$ ) and SDS-PAGE (c and $\mathbf{d})$. Blots were probed with anti-PrP antibodies 3F4 (a and $\mathbf{c}$ ) and 8B4 (b and $\mathbf{d})$. Purified $\beta$-hPrP90-231 (100 ng, lanes $1 \mathrm{a}-\mathrm{c}$ ) was subjected to both electrophoretic conditions, to evidence its apparent molecular weight (c, lane 1), and native aggregation state (a, lane 1). No signal is detected in lane $1 \mathbf{b}$, as $8 \mathrm{~B} 4$ antibody does not recognize $\beta$-hPrP90-231. Blot a shows 3F4-immunoreactive aggregates after 1 and 4 days of treatment with hPrP90-231. Blot $\mathbf{b}$ shows that no significant $8 \mathrm{~B} 4$-reactive aggregates are induced by $\beta$-hPrP90-231 treatment. SDS-PAGE shows that, although $\beta-\mathrm{hPrP90-231}$ monomer is recovered within SH-SY5Y cytoplasm after 1 and 4 days of treatment (blot $\mathbf{c}$ ), the expression of endogenous $\mathrm{PrPC}^{\mathrm{C}}$ is unmodified (blot d)

Cells were lysed in non-denaturing conditions, insoluble proteins collected by centrifugation, and the amount of hPrP90-231 in soluble and insoluble fractions determined by immunoblotting. $\mathrm{PrP}^{\mathrm{C}}$ was recovered in the detergentsoluble fraction at all the treatment times (Figure 4a), whereas hPrP90-231 was detected only in the insoluble fraction of cell lysate, in which it accumulates in a timedependent manner (Figure 4b).

Internalized hPrP90-231 displays partial resistance to proteolysis. We measured PK sensitivity of internalized hPrP90-231 to obtain an index of resistance to lysosomal degradation. Cells treated with vehicle or hPrP90-231 were lysed under non-denaturing conditions, in the absence of protease inhibitors, and proteins incubated with increasing amounts of PK (Figure 5a). In the absence of PK treatment, endogenous $\mathrm{PrP}^{\mathrm{C}}$ was detected without alterations induced by hPrP90-231 treatment. Conversely, a large 3F4immunoreactive band was detectable in cell lysates after treatment with hPrP90-231, showing an apparent molecular weight matching with that of hPrP90-231 (16 kDa). Although $\mathrm{PrP}^{\mathrm{C}}$ was completely degraded by $\mathrm{PK}(1 \mu \mathrm{g})$, the complete digestion of the bona fide intracellular hPrP90-231 required a 10-fold higher PK concentration. The marked difference in proteolysis resistance between $\mathrm{PrP}^{\mathrm{C}}$ and internalized hPrP90-231 was further demonstrated using the cell

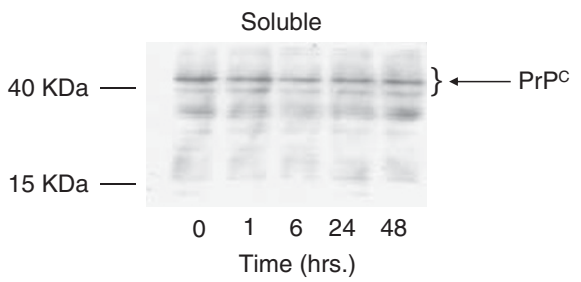

b

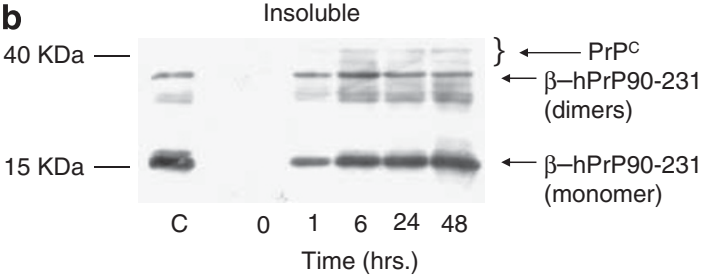

Figure 4 Internalized $\beta$-hPrP90-231 is insoluble in non-denaturing detergents. Cells were treated with $\beta$-hPrP90-231 $(1 \mu \mathrm{M})$ for $1-48 \mathrm{~h}$. Cells were collected in non-denaturing lysis buffer, cleared of debris, and centrifuged at $16000 \times g$ for $45 \mathrm{~min}$. Supernatants (a) and pellets (b) $(50 \mu \mathrm{g})$ were analyzed by western blot using anti-PrP monoclonal antibody 3F4. Purified $\beta$-hPrP90-231 (100 ng) (lane C) was loaded to compare the electrophoretic run of PrP fragment before and after intracellular uptake. $\beta$-hPrP90-231-treated cells evidence increased 3F4-immunoreative bands having an apparent molecular weight of $16 \mathrm{KDa}$, corresponding to $\beta$-hPrP90-231 (resolved in lane C). Intracellular $\beta$-hPrP90-231 is recovered in a time-dependent manner in the pellets, indicating that internalized pepetide is completely insoluble (b). Conversely, endogenous $\mathrm{PrP}^{\mathrm{C}}$ is recovered almost completely in the soluble fraction (a) and does not modify its expression upon cell treatment with $\beta-\mathrm{hPrP90}-231$

blotting technique. Treated cells were firmly pressed on lysis buffer-soaked nitrocellulose membrane to transfer their protein content as a sort of fingerprint; membranes were then treated with PK before being probed with 3F4 and 8B4 antibodies (Figure 6). Immunoblots revealed that cells exposed to hPrP90-231 retain a 3F4-immunoreactive signal, resistant to $\mathrm{PK}$ digestion (up to $0.5 \mu \mathrm{g} / \mathrm{ml}$, upper panel), whereas vehicle-treated cells showed an almost complete loss of 3F4 signal. Using the 8B4 antibody (lower panel), PK treatment markedly reduced the immunoreactive signal in both vehicle and hPrP90-231-treated samples, indicating a high $\mathrm{PrP}^{\mathrm{C}}$ sensitivity to proteolysis that is not modified by cell exposure to hPrP90-231.

hPrP90-231 is internalized into acidic organelles. SH-SY5Y cells plated into glass-bottom Petri dishes were treated with hPrP90-231-FITC, loaded with lysotracker red DND-99 that stains endosomal-lysosomal vesicles and analyzed by confocal microscopy in live cell imaging. Intracellular hPrP90231-FITC was detected as fluorescent clusters colocalized with lysotracker (Figure 7a). Lysotracker-positive and hPrP90-231FITC-loaded vesicles showed larger size than those that do not contain the peptide. To better analyze lysosomal involvement in hPrP90-231 effects, we tested, by immunoblotting, the expression of the active form of the lysosomal enzyme CD. The amount of active CD was greatly increased after $2 \mathrm{~h}$, peaked at $6 \mathrm{~h}$, and was still upregulated after 2 days of hPrP90231 treatment (Figure 7b), with a significant temporal relationship with intracellular accumulation of hPrP90-231 (Figure 4b). These data provide important evidence that cell 


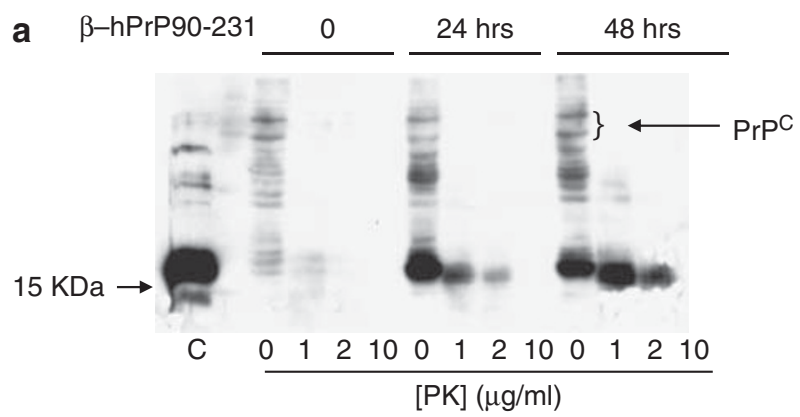

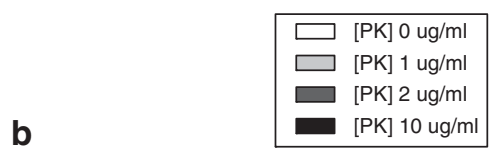

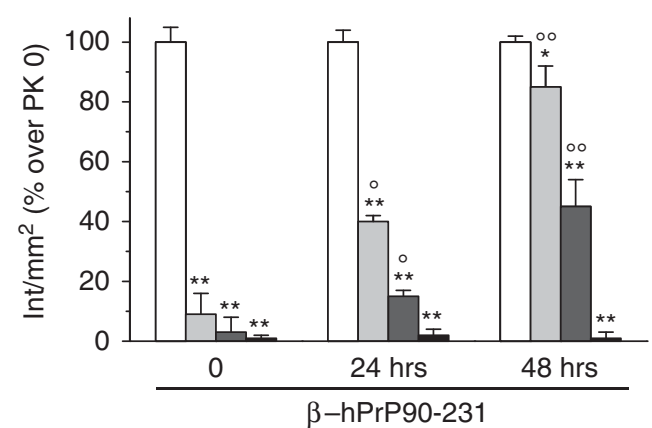

Figure 5 Internalized $\beta$-hPrP90-231 is partly PK resistant. (a) Cells treated with PBS or $\beta$-hPrP90-231 ( $1 \mu \mathrm{M})$ for 24 and $48 \mathrm{~h}$ were collected in non-denaturing lysis buffer, without protease inhibitors. Proteins for each sample $(100 \mu \mathrm{g})$ were digested with increasing concentrations of PK $(1,2$, and $10 \mu \mathrm{g} / \mathrm{ml})$ at $37^{\circ} \mathrm{C}$ for $30 \mathrm{~min}$. $\mathrm{PrP}^{\mathrm{C}}$ and $\beta$-hPrP90-231 digestion fragments were resolved by $15 \%$ SDS-PAGE using the anti-PrP antibody 3F4. $\beta$-hPrP90-231 (100 ng) was loaded to compare the electrophoretic run of PrP fragment before and after intracellular uptake (lane C). Control cells evidence a faint 3F4-immunoreactive signal between 35 and $45 \mathrm{kDa}$, corresponding to $\operatorname{PrP}^{\mathrm{C}}$, that is almost fully digested by PK. Cell treatment with $\beta$-hPrP90-231 for 24 and $48 \mathrm{~h}$ induced the appearance of a $16 \mathrm{kDa}$ band corresponding to internalized PrP fragment that showed a full digestion only at $10 \mu \mathrm{g} / \mathrm{ml} \mathrm{PK}$, indicating that internalized $\beta$-hPrP90-231 is significantly more protease-resistant than $\mathrm{PrP}^{\mathrm{C}}$. (b) Densitometric analysis of $3 \mathrm{~F} 4$ signal in untreated (white columns) and PK-digested samples (light gray, gray, and black columns). Time 0 , in the absence of $\beta$-hPrP90-231, indicates PK effects on PrPC (MW 35$45 \mathrm{kDa}$ ). Plot shows that intracellular $\beta-\mathrm{hPrP} 90-231$ resistance is higher than that of $\operatorname{PrP}^{\mathrm{C}}$ and increases with treatment time. Values $(n=3)$ represent OD intensity $/ \mathrm{mm}^{2}$ and expressed as percentage of respective PK-undigested samples. ${ }^{*} P<0.05$ and ${ }^{* *} P<0.01$ versus respective undigested controls; ${ }^{\circ} P<0.05,{ }^{00} P<0.01$ versus corresponding PK digestion of vehicle-treated cells

proteolytic machinery is activated in response to hPrP90-231 (i.e. accumulation within lysosomes and increase of CD activity), but suggest that it is not sufficient to remove hPrP90-231 from cells.

hPrP90-231 treatment induces loss of lysosomal membrane impermeability. To test whether lysosome overloading with protease-resistant hPrP90-231 aggregates is responsible for $\mathrm{SH}-\mathrm{SY} 5 \mathrm{Y}$ apoptosis, we evaluated the effects of PrP fragment internalization on lysosome membrane impermeability. By confocal microscopy, we monitored the intracellular distribution of the membrane-

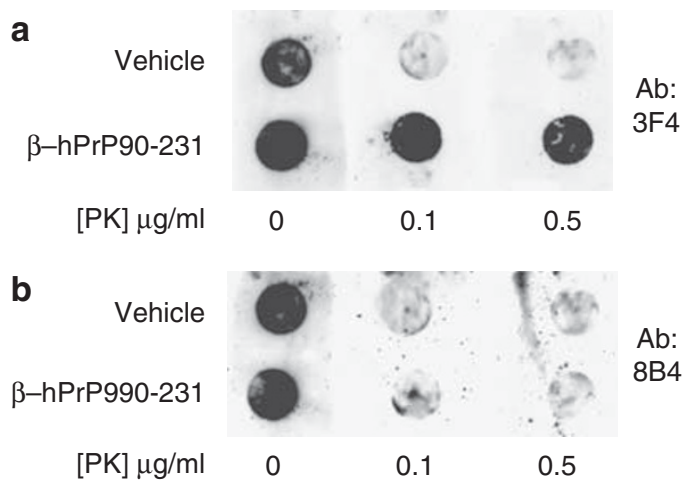

Figure 6 Cell blotting analysis of internalized $\beta$-hPrP90-231 PK sensitivity. Cells were plated on glass coverslips, treated with vehicle (PBS) or $\beta$-hPrP90-231 $(1 \mu \mathrm{M})$ for $24 \mathrm{~h}$, and processed for cell blotting (see Materials and methods). Blots were treated with increasing concentrations of PK and probed with anti-PrP antibodies 3F4 (a) and 8B4 (b). Vehicle-treated cells show immunoreactivity for both antibodies that is strongly reduced by PK treatment. $\beta$-hPrP90-231 treatment induces a significant PK resistance, evidenced only by $3 \mathrm{~F} 4$ antibody

impermeable liquid-phase dye LY. It is taken up by endocytosis and accumulates within recycling endosomes, late endosomes, and lysosomes. ${ }^{19}$ In healthy cells, lysosomes retain membrane impermeability that prevents LY leakage in the cytosol, whereas lysosome-mediated apoptosis is preceded by their membrane permeabilization and release of LY and hydrolytic enzymes. ${ }^{24} \mathrm{SH}-\mathrm{SY} 5 Y$ cells were treated with vehicle or hPrP90-231 before being loaded with LY and analyzed by confocal microscopy (Figure 7c). To demonstrate LY loading in lysosomes, we also labeled SH-SY5Y cells with lysotracker. Live cell analysis revealed an almost complete fluorescence overlapping between lysotracker and LY in control cells, indicating that LY efficiently loaded lysosomes, demonstrating their integrity. Conversely, hPrP90-231-treated cells evidenced LY diffuse staining within the cytoplasm, often losing the colocalization with lysotracker (Figure 7c, lower panel). Thus, lysosomal hydrolases, including CD that is activated after hPrP90-231 treatment (Figure 7b), may diffuse from lysosomes into the cytosol to induce apoptosis. Hence, we investigated the possibility that pharmacological blockade of CD could inhibit the proapoptotic activity of hPrP90-231. For this purpose, we pretreated SH-SY5Y cells with pepstatin A (Pep A), a specific inhibitor of CD, before the incubation with hPrP90-231, and measured cell viability and DNA cleavage by 3-(4,5dimethylthiazol-2-yl)2,5, diphenyl tetrazolium bromide (MTT) reduction test and oligonucleosome ELISA, respectively, (Table 2). Treatment with hPrP90-231 reduced cell viability and increased DNA cleavage as compared with controls. Both the effects were significant, although not completely reduced by pre-treatment with Pep A $(10 \mu \mathrm{M})$. Lower or higher concentrations of Pep A were either ineffective or per se cytotoxic, respectively, (data not shown).

These data suggest that CD activation takes part in the transduction of the proapoptotic activity of hPrP90-231, although other CD-independent events could participate to this process. More importantly, the demonstration of $C D$ involvement in hPrP90-231 toxicity argues in favor of an active role of lysosomal permeabilization in the induction of 
a

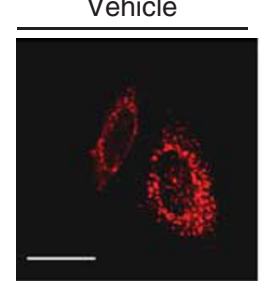

Lysotracker

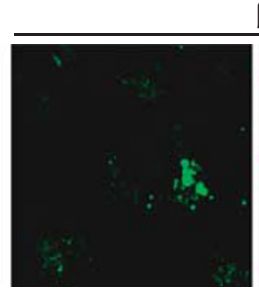

FITC

$\beta$-hPrP90-231-FITC

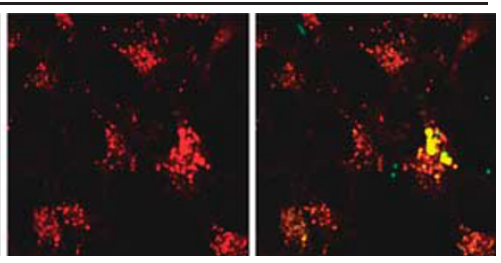

Lysotracker

merge

b

c

Vehicle
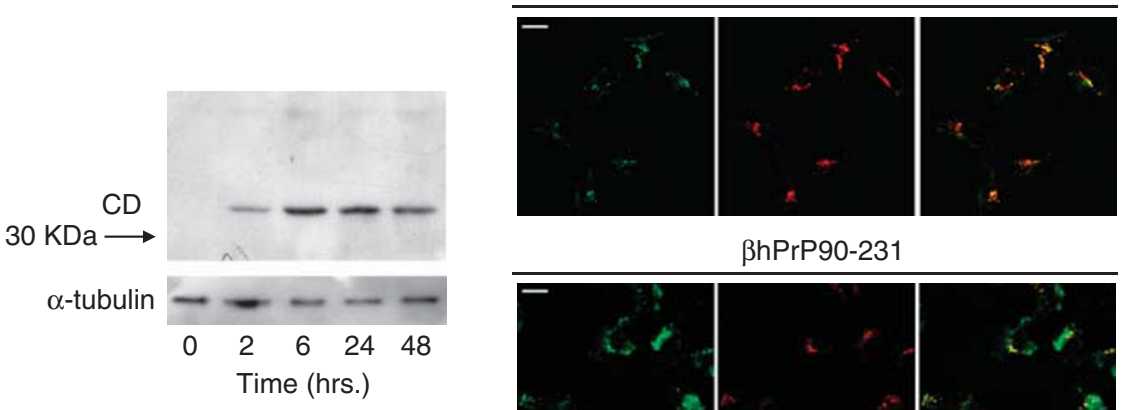

BhPrP90-231

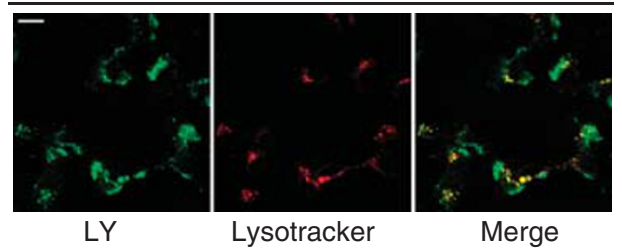

Figure 7 Intracellular $\beta$-hPrP90-231 activates endosomal-lysosomal system. (a) $\beta$-hPrP90-231-FITC accumulates into endosomal-lysosomal vesicles. Cells were treated with vehicle and $\beta$-hPrP90-231FITC $(1 \mu \mathrm{M})$ for $24 \mathrm{~h}$ and counterstained with lysotracker red DND-99, before being observed in live cell confocal microscopy. Cells treated with $\beta$-hPrP90-231-FITC show fluorescent round clusters that almost completely colocalize with lysotracker. Vehicle-treated cells were stained with lysotracker red to provide images of lysosomes distribution and size in SH-SY5Y cells. (b) $\beta$-hPrP90-231 elicits the expression of active CD. Cells were treated for 2-48 h with $\mathrm{hPrP90-231}$ $(1 \mu \mathrm{M})$. The amount of active CD (MW $33 \mathrm{kDa}$ ) was detected by SDS-PAGE (10\%), loading $50 \mu \mathrm{g}$ of cell proteins/lane. A separate set of samples (10 $\mu \mathrm{g} / \mathrm{lane})$ was probed with the monoclonal anti- $\alpha$-tubulin to normalize protein content. The expression of $33 \mathrm{kDa} C D$, corresponding to the mature active form, is significantly increased after $2 \mathrm{~h}$, reaches a sustained plateau after $6 \mathrm{~h}$, and lasts up to $48 \mathrm{~h}$ of treatment. (c) $\beta$-hPrP90-231 treatment causes loss of lysosome membrane impermeability. Cells were treated for 3 days with vehicle (PBS) or $\beta-\mathrm{hPrP90}-231(1 \mu \mathrm{M})$. In the last $15 \mathrm{~h}$ of treatment, cells were loaded with $100 \mu \mathrm{g} / \mathrm{ml}$ of $\mathrm{LY}$. At $15 \mathrm{~min}$ before confocal microscope analysis, cells were loaded with lysotracker red DND-99 (50 nM). Control cells evidenced a vesicular distribution of LY that almost completely overlaps with lysotracker fluorescence, indicating an efficient loading of $\mathrm{LY}$ in endosomal-lysosomal vesicles (upper panels). $\beta$-hPrP90-231-treated cells exhibited a diffuse LY staining within the cytoplasm outside lysotrackerpositive vesicles (lower panel), indicating that LY has been redistributed in the cytosol following the loss of lysosomal membrane impermeability. (Scale bars $=10 \mu \mathrm{m})$

Table 2 Cathepsin D inhibition by pepstatin A inhibits SH-SY5Y cell death and induction of apoptosis induced by $\beta$-hPrP90-231

\begin{tabular}{lcc}
\hline Treatment & $\begin{array}{c}\text { Cell viability } \\
\text { (\% of control) }\end{array}$ & $\begin{array}{c}\text { Apoptosis } \\
\text { (\% of control) }\end{array}$ \\
\hline Control & 100 & 100 \\
$\beta$-hPrP90-231 & $68 \pm 0.5^{\star}$ & $297 \pm 0.12^{\star *}$ \\
$\beta$-hPrP90-231+pepstatin A & $80 \pm 0.7^{\star}$ O & $218 \pm 0.09^{\star *}$ O० \\
Pepstatin A & $99 \pm 0.2$ & $108 \pm 0.06$
\end{tabular}

Cells were pretreated with pepstatin $\mathrm{A}(10 \mu \mathrm{M})$ at $1 \mathrm{~h}$ before $\beta-\mathrm{hPrP} 90-231$ $(1 \mu \mathrm{M})$. Cell viability was measured by MTT reduction assay, and the extent of apoptosis was detected using cytosolic oligonucleosome ELISA Data were expressed as percentage of PBS-treated control cells and represents the average of three independent experiments performed in quadruplicate ${ }^{\star} P<0.05$, ${ }^{\star *} P<0.01$ versus cont. values. ${ }^{\circ} P<0.05,{ }^{\circ}{ }^{\circ} P<0.01$ versus hPrP90-231-treated values

apoptosis, likely due to accumulation of aggregated, protease-resistant PrP fragment.

\section{Discussion}

The relationship between PrP misfolding and neuronal death is still debated. ${ }^{25}$ In particular, the relevance of extracellular deposition of $\mathrm{PrP}^{\mathrm{Sc}}$ in disease progression is controversial, being proposed to represent either a primary pathogenic event, an epiphenomenon of neuronal death or a cell defense reaction. ${ }^{26}$ The endosomal-lysosomal system represents the site of $\mathrm{PrP}^{\mathrm{C}}-\mathrm{PrP}^{\mathrm{Sc}}$ interaction responsible for $\mathrm{PrP}^{\mathrm{C}}$ misfolding and $\mathrm{PrP}^{\mathrm{Sc}}$ partial cleavage. ${ }^{27}$ Vesicular trafficking from plasma membrane to lysosomes sustains intracellular accumulation of $\mathrm{PrP}^{\mathrm{Sc}},{ }^{28}$ leads to lysosomal impairment, and might represent a mechanism of prion neurodegeneration. ${ }^{15,16}$ Impairment of lysosomal activity also contributes to Alzheimer disease pathogenesis ${ }^{29}$ with $\mathrm{A} \beta$ peptides functioning as seeds for amyloid formation in acidic vesicles. ${ }^{22}$

In TSE, PrP ${ }^{S c}$ uptake in neurons occurs in the early phases of disease, allowing the formation of new $\mathrm{PrP}^{\mathrm{Sc}}$ molecule and their diffusion into surrounding neurons. ${ }^{30,31}$ We characterized the events involved in $\mathrm{PrP}^{\mathrm{Sc}}$ internalization as a cause of neuronal death, using hPrP90-231 as an in vitro model of prion neurotoxicity. This fragment encompasses the amino acid sequence of peptides derived from $\mathrm{PrP}^{\mathrm{Sc}}$ partial digestion that occurs in prion-infected brains. ${ }^{32}$ There are several similarities between recombinant $\operatorname{PrP}$ fragments and $\mathrm{PrP}^{\mathrm{Sc}}$, including structural flexibility, ${ }^{4}$ structure-dependent in vitro cytotoxicity, ${ }^{3,33}$ and, in particular experimental conditions, infectivity, ${ }^{5,6}$ supporting the hypothesis that in TSE patient 
brains, hPrP90-231-like fragments might have a causative role in neuronal apoptosis.

We report that hPrP90-231 intracellular aggregates within acidic vesicles are insoluble and partially resistant to proteolysis. Using hPrP90-231-FITC, live cell imaging, and confocal microscopy, we were able to discriminate between the exogenous fragment and endogenous $\operatorname{PrP}^{\mathrm{C}}$, and avoid possible artifacts caused by cell fixation. We show that hPrP90-231 binding to plasma membrane occurs within few minutes and is followed by accumulation in intracellular protein clusters that was dependent on the refolding of the peptide in a $\beta$-sheet-rich conformer. We never observed persistent membrane binding of hPrP90-231-FITC or significant accumulation of the protein across the plasma membrane, the membrane-hPrP90-231 interaction being mainly involved in the internalization of the PrP fragment. To verify whether hPrP90-231 aggregate resistance to lysosomal proteolytic activity may be responsible for hPrP90-231 intracellular accumulation cytotoxicity, we analyzed three biochemical parameters of the internalized peptide: aggregation state, insolubility, and PK sensitivity, all of them reliably used to discriminate $\operatorname{PrP}^{\mathrm{Sc}}$ from $\operatorname{PrP}^{\mathrm{C}}$. 1,34 The extent of aggregation of internalized hPrP90-231, in semi-denaturing detergent-agarose gel electrophoresis, was detected, as 3F4immunoreactive signal smeared through all the lane, indicating the presence of aggregates composed by heterogeneous number of molecules. 8B4 antibody, recognizing only endogenous $\mathrm{PrP}^{\mathrm{C}}$, did not reveal aggregation, indicating that most, if not all, 3F4 immunoreactivity detects hPrP90-231. However, we cannot exclude the possibility that $\operatorname{PrP}^{\mathrm{C}}$ may function as a seed to allow or, at least, favor hPrP90-231 aggregation. The involvement of endogenous $\mathrm{PrP}^{\mathrm{C}}$ in $\mathrm{hPrP} 90-231$ aggregation is an intriguing issue deserving further investigations.

Upon internalization, hPrP90-231-FITC is trapped into phospholipid-surrounded vesicles having features of late endosomes or lysosomes. Moreover, CD activation occurred after cell exposure to hPrP90-231, strengthening the hypothesis that SH-SY5Y cells actively uptake hPrP90-231 and activate lysosome-mediated proteolysis, although hPrP90231 aggregates are not hampered by exposure to lysosomal proteolytic activity. Using non-denaturing conditions to preserve the aggregation state of internalized hPrP90-231, we show that hPrP90-231 intracellular deposits are insoluble in non-denaturing detergents and show a significant higher PK resistance than endogenous $\mathrm{PrP}^{\mathrm{C}}$. The finding that these biochemical features of hPrP90-231, previously characterized in cell-free models, ${ }^{3,8}$ are enhanced after accumulation in lyso-phagosomes, indicates that the proteolytic machinery of $\mathrm{SH}-\mathrm{SY} 5 \mathrm{Y}$ cells is impaired by the progressive internalization of high quantities of hPrP90-231 and this alteration could represent a crucial event to trigger apoptosis. In particular, hPrP90-231 partial resistance to PK likely reflects its ability to withstand lysosomal degradation once endocyted. Lysosomes have been involved in TSE pathogenesis, as high number of endosomal-lysosomal vesicles containing $\mathrm{PrP}^{\mathrm{Sc}}$ are detected in brains of scrapie-infected mice and CJDaffected humans. ${ }^{2,15,16}$

Lysosome-mediated apoptosis occurs when lysosome membranes become permeable to proteolytic enzymes that, once released, activate caspases or other proapoptotic proteins. ${ }^{35}$ Lysosomal membrane permeabilization occurs in different neurotoxic conditions, ${ }^{18}$ including $\mathrm{A} \beta_{1-42}$ exposure. ${ }^{19}$ We report that intracellular hPrP90-231 accumulation and the consequent lysosome damage correlates with the onset of apoptosis. We calculated that at each time point analyzed, about $10 \%$ of apoptotic cells were present in hPrP90-231-treated cultures, although the required washing steps may detach dying cells, underestimating the incidence of apoptosis. We associated confocal microscopy observations to flow cytometry results: FACS analysis revealed that about $99 \%$ of total cells was stained with hPrP90-231-FITC, but was unable to discriminate the majority of cells having internalized, at a given time point, small amounts of hPrP90231 from those that have internalized massive amount of hPrP90-231-FITC. By confocal living cell observation, we revealed a threshold of hPrP90-231-FITC internalization required to trigger the apoptotic cascade.

In search of a link between intralysosomal aggregation of protease-insensitive hPrP90-231 and activation of lysosomedependent apoptosis, we measured lysosome ability to segregate LY after exposure to hPrP90-231. We observed that hPrP90-231 treatment affected vesicular distribution of LY inducing its cytoplasmic diffusion. Whether LY diffusion from lysosomes is a direct consequence of hPrP90-231 accumulation in the organelles or results from a more complex toxic pathway triggered by PrP fragment, remains to be established. However, we show that lysosomal enzymes, like $\mathrm{CD}$, are activated after hPrP90-231 treatment and, once released into the cytosol, could start the apoptotic program. Finally, a more direct relationship between lysosomal dysfunction and hPrP90-231-induced cell death was demonstrated by the reduction of SH-SY5 apoptosis in the presence of the CD inhibitor Pep $A$, although, the effect being incomplete, other intracellular effectors might have a role in transducing cytotoxic signals of hPrP90-231. hPrP90-231 interaction with plasma membrane could also trigger apoptosis through the perturbation of ion homeostasis ${ }^{36,37}$ or cell responsiveness to neuroprotective factors. ${ }^{10} \mathrm{We}$ recently demonstrated that hPrP90-231 leads to cell apoptosis affecting the balance between MAP kinase activities, inhibiting ERK1/2 and activating p38. ${ }^{10}$ The molecular events that precedes hPrP90-231 ERK1/2 inhibition are not identified, and a link between lysosomal permeabilization and ERK1/2/ p38 imbalance has not been demonstrated.

Another important issue concerns the effect of hPrP90-231 aggregation state on the cells' ability to internalize the fragment. We demonstrated that large, but aggregated or amyloid fibrils of hPrP90-231 cannot be internalized and cause cell death. ${ }^{12}$ Thus, we propose that hPrP90-231 endocytosis is hampered by its extracellular aggregation, although the threshold limit of this phenomenon is still unknown. In this regard, the finding that intracellular hPrP90-231 formed insoluble and PK-resistant aggregates is particularly relevant, as it indicates that the aggregation process of the protein has been allowed, if not favored, by the intracellular milieu.

In conclusion, we propose a model in which neurotoxic PrP is taken up by neurons in oligomeric soluble forms and accumulate in acidic vesicles, in which aggregation takes 
place. The final destiny of the cell, survival, or apoptosis, is dependent on the amount of internalized PrP molecules and the capacity of these aggregates to cause lysosomedependent apoptosis.

\section{Materials and Methods}

Reagents and antibodies. FITC, lysotracker red DND-99, Annexin-V Alexa Fluor 594 conjugate, Dil, LY CH, and Alexa Fluor-conjugated secondary antibodies were from Molecular Probes-Invitrogen (Milano, Italy); protease $\mathrm{K}$ and anti- $\alpha$-tubulin mouse monoclonal antibody were from Sigma-Aldrich (Milano, Italy); anti-PrP mouse monoclonal antibody 3F4 was from Signet (London, UK), anti-PrP mouse monoclonal antibody $8 \mathrm{~B} 4$ and anti-CD rabbit polyclonal antibody were from Santa Cruz, (Santa Cruz, CA, USA); horse peroxidase-linked anti-mouse and anti-rabbit secondary antibodies were from GE Healthcare (Milano, Italy).

Recombinant hPrP90-231. The PrP fragment was obtained and purified as previously described. ${ }^{7}$ Before addition to cultures, hPrP90-231 was incubated at $53^{\circ} \mathrm{C}$ for $1 \mathrm{~h}^{4}$ that causes its refolding in a $\beta$-sheet-rich conformer (native structure: $\alpha$-helix $42.4 \%$, $\beta$-sheet $6.8 \%$; after thermal denaturation: $\alpha$-helix $8.6 \%, \beta$-sheet $58.8 \%)$

Fluorescent $\mathrm{hPrP90-231}$. FITC tag of $\mathrm{hPrP90}-231$ was performed by adding $1 \mathrm{mg}$ of FITC in $100 \mu \mathrm{l}$ DMSO to $5 \mathrm{ml}$ of hPrP90-231 solution $(0.25 \mathrm{mg} / \mathrm{ml}$ in PBS, $\mathrm{pH}$ 8.0). Incubation was carried for $30 \mathrm{~min}$ under dark-adapted rotation. The reaction was stopped by adding glycine to reach a final concentration of $10 \mu \mathrm{M}$; fluorescent hPrP90-231 (hPrP90-231-FITC) was separated by unbound FITC and concentrated by three centrifugation steps in Millipore (Cork, Ireland) centricon tubes $(10 \mathrm{ml}$, $10 \mathrm{kDa}$ mesh). $\mathrm{hPrP90}-231-\mathrm{FITC}$ was used freshly or stored at $-80^{\circ} \mathrm{C}$ for not longer than 15 days. Unless otherwise specified, hPrP90-231 was incubated for $1 \mathrm{~h}$ at $53^{\circ} \mathrm{C}$ before FITC addition.

Cell cultures and treatments. SH-SY5Y human neuroblastoma cells were cultured in Mem/F12 medium (Euroclone, Milano, Italy) supplemented with $15 \%$ fetal bovine serum (FBS) (Gibco-Invitrogen, Milano, Italy), $2 \mathrm{mM}$ glutamine (Euroclone), pen/strep $100 \mathrm{mg} / \mathrm{ml}$ (Euroclone) and grown in $5 \% \mathrm{CO}_{2}$ atmosphere at $37^{\circ} \mathrm{C}$.

Treatments. At $24 \mathrm{~h}$ after plating, unless otherwise stated, culture medium was replaced with a fresh medium containing a reduced $(2 \%)$ percentage of FBS to induce growth arrest and minimize spontaneous apoptosis that serum withdrawal causes in this cell model; ${ }^{38}$ then, cells were treated by adding hPrP90-231 or hPrP90-231-FITC directly to the medium.

\section{Confocal analysis}

Immunostaining. Cells were plated on glass coverslips (Corning-Costar, Celbio, Milano, Italy) and treated with hPrP90-231-FITC; to evidence cell shape, cells were fixed in cold methanol and immunostained with anti- $\alpha$-tubulin antibody by following standard procedures.

Live cell imaging. Cells were plated in glass-bottom Petri dishes (Iwaki, Bibby Scientific, Milano, Italy) and loaded with $100 \mathrm{ng} / \mathrm{ml}$ of Dil for $1 \mathrm{~h}$. Cells were then rinsed in PBS and then treated with hPrP90-231-FITC in 2\% FBS-containing culture medium. At given time points, live cells were washed with serum-free medium and observed using a inverted fluorescent microscope (Nikon Eclipse TE300, Langen, Germany) equipped with a laser scanning confocal system (Bio-Rad MRC1024 ES, Bio-Rad Laboratories, Milano, Italy). When specified, lysotracker red DND-99 $(50 \mathrm{nM})$ was added to cell cultures $15 \mathrm{~min}$ before the confocal observation.

MTT reduction assay. Mitochondrial function, as index of cell viability, was evaluated by measuring MTT reduction into purple formazan crystals. ${ }^{38}$ Cells were incubated with $0.25 \mathrm{mg} / \mathrm{ml} \mathrm{MTT}$ in serum-free medium at $37^{\circ} \mathrm{C}$ for $2 \mathrm{~h}$. Medium was removed and formazan was dissolved in DMSO; values of absorbance were read in a spectrophotometer at $570 \mathrm{~nm}$.

\section{Apoptosis detection}

Oligonucleosome release. The assay (cell death detection ELISA, Roche, Monza, Italy) is based on a quantitative sandwich enzyme immunoassay principle that determines the amount of mono-and oligonucleosomes, released in the cytoplasm by apoptotic endonucleases. ${ }^{3}$ Briefly, after treatments, cytosolic fraction of cell lysates were placed into streptavidin-coated microplate wells (Roche) and incubated with a mixture of biotinylated anti-histone antibodies and peroxidaselinked anti-DNA antibodies (Roche). Incubation and washing steps were performed according to manufacturer's instructions; peroxidase detection was determined spectrophotometrically with ABTS as substrate.

Annexin-V binding test. This test evaluates apoptosis-induced exposure of phosphatidylserine (PS) at the outer face of plasma membrane by staining cells with the PS-binding protein annexin $\mathrm{V}^{39}$

Flow cytometry. We used Annexin V-APC Apoptosis Detection Kit I (BD Biosciences, Oxford, UK) according to the manufacturer's instructions. Briefly, control and hPrP90-231-FITC-treated cells were trypsinized, washed in PBS, and resuspended in serum-free medium. Annexin $V$ was added to the cell preparations $\left(10^{5}\right.$ cells) and incubated for $15 \mathrm{~min}$ in the dark at room temperature (r.t.). Serumfree medium was then added to each tube, and the samples were analyzed using Cyan ADP cytofluorimeter (Beckman-Coulter, Brea, CA, USA). For each sample, 20000 events were acquired. The data was analyzed using Summit 4.3.1 software (Dakocytomation, Ely, Cambridgeshire, UK).

In situ studies. Cells were plated into glass-bottom Petri dishes (Iwaki) and treated with hPrP90-231-FITC. After treatments, cells were washed three times with PBS and incubated with $1 \mathrm{ml}$ of annexin-V binding buffer $(140 \mathrm{mM} \mathrm{NaCl}, 10 \mathrm{mM}$ HEPES, $2.5 \mathrm{mM} \mathrm{CaCl}_{2}, \mathrm{pH} 7.4$ ); subsequently, $50 \mu \mathrm{l}$ of annexin $\mathrm{V}$ Alexa Fluor conjugate 594 antibody is added for $20 \mathrm{~min}$ at r.t. After three washes with PBS, $1 \mathrm{ml}$ of $2 \%$ FBS culture medium was added to allow observation of live cells under the confocal fluorescence microscopy. Although healthy cells evidence a scattered, faint fluorescent signal, apoptotic cells show a fluorescent rim in correspondence with the plasma membrane, indicating PS exposure.

Lysosome permeability assay. Cells were plated in glass-bottom Petri dishes (Iwaki) and treated with hPrP90-231 $(1 \mu \mathrm{M})$. Then, cells were loaded overnight with $100 \mu \mathrm{g} / \mathrm{ml}$ of the cell impermeable liquid-phase tracer LY (Molecular Probes) in $2 \%$ FBS culture medium. After three washing steps, LY fluorescence was analyzed by confocal laser scanning. In healthy cells a vesicular distribution of $L Y$ is observed, whereas lysosome membrane permeabilization results in a cytosolic release of LY and a diffused cytoplasmic fluorescence. ${ }^{19}$

hPrP90-231 solubility assay. Cells were plated on $100 \mathrm{~mm} \varnothing$ Petri dishes and treated for $0,1,6,24$, and $48 \mathrm{~h}$ with $\mathrm{hPrP} 90-231(1 \mu \mathrm{M})$. After treatments, cells were lysed in buffer $(20 \mathrm{mM}$ Tris- $\mathrm{HCl}, \mathrm{pH} 8,130 \mathrm{mM} \mathrm{NaCl}, 2 \mathrm{mM}$ EDTA, $0.5 \%$ Triton $\mathrm{X}-100,0.5 \%$ NP-40, $0.2 \%$ sodium deoxycholate, PMSF, protease inhibitor cocktail (Roche)) and large debris were removed by centrifugation at $2000 \times g$ for $5 \mathrm{~min}$. Supernatants were subjected to centrifugation at $16000 \times g$ for $45 \mathrm{~min}$. Protein content was evaluated by Bradford assay. Samples from re-suspended pellets and supernatants were boiled in the Laemmli buffer and resolved by SDS-PAGE. PrPC and $\mathrm{hPrP} 90-231$ content was determined by immunoblotting using the anti-PrP mouse monoclonal antibody 3F4.

Intracellular hPrP90-231 PK resistance assay. Internalized hPrP90231 resistance to proteolysis was revealed by immunoblotting. Cells were plated on $100 \mathrm{~mm} \varnothing$ Petri dishes, treated with PBS or hPrP90-231 $(1 \mu \mathrm{M})$ for 24 and $48 \mathrm{~h}$, and collected in lysis buffer without protease inhibitors. Total lysates were cleared of nuclei/cell debris by brief centrifugation before protein content determination using the Bradford assay (Bio-Rad). Digestion was performed treating $100 \mu \mathrm{g}$ of protein for each sample with increasing concentrations of PK (final concentration: 1, 2, $10 \mu \mathrm{g} / \mathrm{ml}$ ) for $30 \mathrm{~min}$ at $37^{\circ} \mathrm{C}$. Digestion was stopped by boiling samples in Laemmli buffer. Digestion profile was detected by subjecting samples to $15 \%$ SDS-PAGE followed by immunoblotting using the anti-PrP mouse monoclonal antibody $3 \mathrm{~F} 4$.

Cell blotting. The intracellular presence of PK-resistant hPrP90-231 was revealed through a modified version of cell blotting technique by Bosque et al. ${ }^{40}$ Cells were plated on $15 \mathrm{~mm} \varnothing$ glass coverslips at $70 \%$ confluence and treated with vehicle or hPrP90-231 $(1 \mu \mathrm{M})$ for $24 \mathrm{~h}$. After treatments, coverslips were gently pressed for $2 \mathrm{~min}$, cells side-down on nitrocellulose soaked in lysis buffer without protease inhibitors. Then membrane was air dried for $1 \mathrm{~h}$, washed in distilled water, and incubated in lysis buffer containing PK $(0.1$ and $0.5 \mu \mathrm{g} / \mathrm{ml})$ for $1 \mathrm{~h}$ at $37^{\circ} \mathrm{C}$ with constant shaking. Digestion was stopped by incubating the blot for $20 \mathrm{~min}$ with $5 \mathrm{mM}$ phenylmethylsulfonyl fluoride in $\mathrm{dH}_{2} \mathrm{O}$ at r.t. Blots were washed and blocked with Tris-buffered saline, containing $5 \%$ non-fat dry milk, and incubated with mouse monoclonal anti-PrP antibodies 8B4 and 3F4, following standard immunoblotting procedures. 
SDS-PAGE immunoblotting. Cell lysates were boiled for $10 \mathrm{~min}$ in Laemmli buffer. Proteins were size fractionated by $10 \%$ or $15 \%$ SDS-PAGE and transferred to a polyvinylidene difluoride membrane (Bio-Rad Laboratories). Membranes were blocked with $0.1 \%$ TBS-Tween containing $5 \%$ skim milk and then probed overnight with the primary antibodies diluted in $0.1 \%$ TBS-Tween $/ 5 \%$ skim milk. Secondary antibodies were horseradish peroxidase-linked anti-mouse or anti-rabbit $\operatorname{lgG}$ antiserum (GE Healthcare). Immunoreactivity was visualized by ECL (GE Healthcare).

Semi-denaturing detergent-agarose gel electrophoresis. hPrP90231 aggregation was evaluated as described,$^{21}$ with modifications. ${ }^{20}$ After $1-4$ days of treatment, cells were lysed in $20 \mathrm{mM}$ Tris- $\mathrm{HCl}, \mathrm{pH} 7.5,130 \mathrm{mM} \mathrm{NaCl}, 2 \mathrm{mM}$ EDTA, 1\% NP-40, $1 \mathrm{mM}$ PMSF, and protease inhibitor cocktail (Roche) and centrifuged to remove nuclei and cell debris (1000 r.p.m., $5 \mathrm{~min}$ ). Samples were incubated for $10 \mathrm{~min}$ at r.t. in loading buffer $(60 \mathrm{mM}$ Tris-HCl, pH 7.5, 20\% glycerol, $2 \%$ SDS, $0.05 \%$ bromophenol blue) and resolved on horizontal agarose gel (1.5\%) in TAE containing $0.1 \%$ SDS. After electrophoresis, proteins were transferred on a nitrocellulose membrane (Hybond ECL, GE Healthcare) and probed with anti-PrP mouse monoclonal antibodies 8B4 and 3F4. Immunoreactivity was detected with a horseradish peroxidase-linked mouse antiserum followed by ECL.

\section{Conflict of interest}

The authors declare no conflict of interest.

Acknowledgements. This study has been supported by grants from the Italian Ministry of University and Research (MIUR-PRIN 2008) and Compagnia di San Paolo (Torino, Italy) to TF.

1. Prusiner SB. Prions. Proc Natl Acad Sci USA 1998; 95: 13363-13383.

2. Van Everbroeck B, Dobbeleir I, De Waele M, De Leenheir E, Lubke U, Martin JJ et al. Extracellular protein deposition correlates with glial activation and oxidative stress in Creutzfeldt-Jakob and Alzheimer's disease. Acta Neuropathol 2004; 108: 194-200.

3. Corsaro A, Paludi D, Villa V, D'Arrigo C, Chiovitti K, Thellung S et al. Conformation dependent pro-apoptotic activity of the recombinant human prion protein fragment 90-231. Int J Immunopathol Pharmacol 2006; 19: 339-356.

4. Swietnicki W, Petersen R, Gambetti P, Surewicz WK. pH-Dependent stability and conformation of the recombinant human prion protein $\operatorname{PrP}(90-231)$. J Biol Chem 1997; 272 27517-27520

5. Legname G, Baskakov IV, Nguyen HO, Riesner D, Cohen FE, DeArmond SJ et al. Synthetic mammalian prions. Science 2004; 305: 673-676.

6. Wang F, Wang X, Yuan CG, Ma J. Generating a prion with bacterially expressed recombinant prion protein. Science 2010; 327: 1132-1135.

7. Corsaro A, Thellung S, Russo C, Villa V, Arena S, D'Adamo MC et al. Expression in E. coli and purification of recombinant fragments of wild type and mutant human prion protein. Neurochem Int 2002; 41: 55-63.

8. Villa V, Corsaro A, Thellung S, Paludi D, Chiovitti K, Venezia V et al. Characterization of the proapoptotic intracellular mechanisms induced by a toxic conformer of the recombinant human prion protein fragment 90-231. Ann N Y Acad Sci 2006; 1090: 276-291.

9. Thellung S, Villa V, Corsaro A, Pellistri F, Venezia V, Russo $C$ et al. ERK $1 / 2$ and p38 MAP kinases control prion protein fragment 90-231-induced astrocyte proliferation and microglia activation. Glia 2007; 55: 1469-1485.

10. Corsaro A, Thellung S, Chiovitti K, Villa V, Simi A, Raggi F et al. Dual modulation of ERK1/2 and p38 MAP kinase activities induced by minocycline reverses the neurotoxic effects of the prion protein fragment 90-231. Neurotox Res 2009; 15: 138-154.

11. Villa V, Tonelli M, Thellung S, Corsaro A, Tasso B, Novelli F et al. Efficacy of novel acridine derivatives in the inhibition of hPrP90-231 prion protein fragment toxicity. Neurotox Res 2011; 19: 556-574

12. Chiovitti $\mathrm{K}$, Corsaro A, Thellung S, Villa V, Paludi D, D'Arrigo $\mathrm{C}$ et al. Intracellular accumulation of a mild-denatured monomer of the human PrP fragment 90-231, as possible mechanism of its neurotoxic effects. J Neurochem 2007; 103: 2597-2609.

13. Bossy-Wetzel E, Schwarzenbacher R, Lipton SA. Molecular pathways to neurodegeneration. Nat Med 2004; 10 (Suppl): S2-S9.

14. Jeffrey M, Goodsir C, McGovern G, Barmada SJ, Medrano AZ, Harris DA. Prion protein with an insertional mutation accumulates on axonal and dendritic plasmalemma and is associated with distinctive ultrastructural changes. Am J Pathol 2009; 175: 1208-1217.

15. Arnold JE, Tipler C, Laszlo L, Hope J, Landon M, Mayer RJ. The abnormal isoform of the prion protein accumulates in late-endosome-like organelles in scrapie-infected mouse brain. J Pathol 1995; 176: 403-411.
16. Kovacs GG, Gelpi E, Strobel T, Ricken G, Nyengaard JR, Bernheimer H et al. Involvement of the endosomal-lysosomal system correlates with regional pathology in Creutzfeldt-Jakob disease. J Neuropathol Exp Neurol 2007; 66: 628-636.

17. Cirman T, Oresic K, Mazovec GD, Turk V, Reed JC, Myers RM et al. Selective disruption of lysosomes in HeLa cells triggers apoptosis mediated by cleavage of Bid by multiple papainlike lysosomal cathepsins. J Biol Chem 2004; 279: 3578-3587.

18. Chwieralski CE, Welte T, Buhling F. Cathepsin-regulated apoptosis. Apoptosis 2006; 11: 143-149.

19. Yang AJ, Chandswangbhuvana D, Margol L, Glabe CG. Loss of endosomal/lysosomal membrane impermeability is an early event in amyloid Abeta1-42 pathogenesis. $J$ Neurosci Res 1998; 52: 691-698.

20. Corsaro A, Anselmi C, Polano M, Aceto A, Florio T, De Nobili M. The interaction of humic substances with the human prion protein fragment $90-231$ affects its protease $\mathrm{K}$ resistance and cell internalization. J Biol Regul Homeost Agents 2010; 24: 27-39.

21. Halfmann $R$, Lindquist $S$. Screening for amyloid aggregation by semi-denaturing detergentagarose gel electrophoresis. J Vis Exp 2008; 17: pii 838

22. Hu X, Crick SL, Bu G, Frieden C, Pappu RV, Lee JM. Amyloid seeds formed by cellular uptake, concentration, and aggregation of the amyloid-beta peptide. Proc Natl Acad Sci USA 2009; 106: 20324-20329.

23. Chiesa R, Piccardo $P$, Ghetti $B$, Harris DA. Neurological illness in transgenic mice expressing a prion protein with an insertional mutation. Neuron 1998; 21: 1339-1351.

24. Eslami $P$, Johnson MF, Terzakaryan E, Chew $C$, Harris-White ME. TGF beta2-induced changes in LRP-1/T beta R-V and the impact on lysosomal $A$ beta uptake and neurotoxicity. Brain Res 2008; 1241: 176-187.

25. Chiesa R, Harris DA. Prion diseases: what is the neurotoxic molecule? Neurobiol Dis 2001; 8: 743-763.

26. Treusch S, Cyr DM, Lindquist S. Amyloid deposits: protection against toxic protein species? Cell Cycle 2009; 8: 1668-1674.

27. Borchelt DR, Taraboulos A, Prusiner SB. Evidence for synthesis of scrapie prion proteins in the endocytic pathway. J Biol Chem 1992; 267: 16188-16199.

28. Doh-Ura K, Iwaki T, Caughey B. Lysosomotropic agents and cysteine protease inhibitors inhibit scrapie-associated prion protein accumulation. J Virol 2000; 74: 4894-4897.

29. Nixon RA, Cataldo AM. Lysosomal system pathways: genes to neurodegeneration in Alzheimer's disease. J Alzheimers Dis 2006; 9: 277-289.

30. Greil CS, Vorberg IM, Ward AE, Meade-White KD, Harris DA, Priola SA. Acute cellular uptake of abnormal prion protein is cell type and scrapie-strain independent. Virology 2008; 379: 284-293.

31. Magalhaes AC, Baron GS, Lee KS, Steele-Mortimer O, Dorward D, Prado MA et al. Uptake and neuritic transport of scrapie prion protein coincident with infection of neuronal cells. $J$ Neurosci 2005; 25: 5207-5216.

32. Notari S, Strammiello R, Capellari S, Giese A, Cescatti M, Grassi J et al. Characterization of truncated forms of abnormal prion protein in Creutzfeldt-Jakob disease. J Biol Chem 2008; 283: 30557-30565

33. Post K, Brown DR, Groschup M, Kretzschmar HA, Riesner D. Neurotoxicity but not infectivity of prion proteins can be induced reversibly in vitro. Arch Virol Suppl 2000; 0 . 265-273.

34. Biasini E, Medrano AZ, Thellung S, Chiesa R, Harris DA. Multiple biochemical similarities between infectious and non-infectious aggregates of a prion protein carrying an octapeptide insertion. J Neurochem 2008; 104: 1293-1308

35. Droga-Mazovec G, Bojic L, Petelin A, Ivanova S, Romih R, Repnik U et al. Cysteine cathepsins trigger caspase-dependent cell death through cleavage of bid and antiapoptotic Bcl-2 homologues. J Biol Chem 2008; 283: 19140-19150.

36. Florio $\mathrm{T}$, Thellung $\mathrm{S}$, Amico $\mathrm{C}$, Robello $\mathrm{M}$, Salmona $\mathrm{M}$, Bugiani $\mathrm{O}$ et al. Prion protein fragment 106-126 induces apoptotic cell death and impairment of L-type voltage-sensitive calcium channel activity in the GH3 cell line. J Neurosci Res 1998; 54: 341-352.

37. Thellung S, Florio T, Villa V, Corsaro A, Arena S, Amico C et al. Apoptotic cell death and impairment of L-type voltage-sensitive calcium channel activity in rat cerebellar granule cells treated with the prion protein fragment 106-126. Neurobiol Dis 2000; 7: 299-309.

38. Thellung S, Villa V, Corsaro A, Arena S, Millo E, Damonte G et al. p38 MAP kinase mediates the cell death induced by PrP106-126 in the SH-SY5Y neuroblastoma cells. Neurobiol Dis 2002; 9: 69-81.

39. van Engeland M, Nieland LJ, Ramaekers FC, Schutte B, Reutelingsperger CP. Annexin $\checkmark$-affinity assay: a review on an apoptosis detection system based on phosphatidyl serine exposure. Cytometry 1998; 31: 1-9.

40. Bosque PJ, Prusiner SB. Cultured cell sublines highly susceptible to prion infection. J Virol 2000; 74: 4377-4386.

Cell Death and Disease is an open-access journal published by Nature Publishing Group. This work is licensed under the Creative Commons Attribution-Noncommercial-No Derivative Works 3.0 Unported License. To view a copy of this license, visit http://creativecommons.org/licenses/by-nc-nd/3.0/ 